Research Article

\title{
Potentially inappropriate medications in hospitalised elderly patients: a cross sectional study
}

\author{
Bhavya NC*, Torgal SS
}

\section{Department of Pharmacology, JNMC, Belgaum-590010, Karnataka, India \\ Received: 27 October 2013 \\ Revised: 13 November 2013 \\ Accepted: 17 November 2013 \\ *Correspondence to: \\ Dr. Bhavya NC, \\ Email: bhavyanc@ rocketmail.com}

(C) 2014 Bhavya NC et al. This is an open-access article distributed under the terms of the Creative Commons Attribution NonCommercial License, which permits unrestricted noncommercial use, distribution, and reproduction in any medium, provided the original work is properly cited.

\begin{abstract}
Background: Information regarding prescribing potentially inappropriate medications (PIMs) in elderly has not been well documented.

Methods: The study was a cross sectional study done by analysing the case records of elderly patients admitted to general medicine and general surgery wards. The data was collected in a proforma which included patient's name age, sex, diagnosis, investigations, and prescription.

Beer's explicit criteria 2012 were used to identify the PIMs in prescriptions. Multivariate logistic regression analysis was done to know the potential factors associated with prescribing PIMs.

Results: The results showed that 44 out of 132 patients received atleast one PIM. The average number of drugs prescribed per patient was 7.5 (range 215). Out of 931 drugs prescribed 63 were found to be potentially inappropriate. Polypharmacy was a major factor associated with prescribing PIMs.

Conclusions: Prescribing potentially inappropriate medications is common in elderly in-patients, polypharmacy being a major factor associated with prescribing PIMs.
\end{abstract}

Keywords: Potentially inappropriate medicines, Beer's criteria, Elderly

\section{INTRODUCTION}

Medications are considered potentially inappropriate when their risks outweigh the benefits. ${ }^{1}$ Exposure to potentially inappropriate medications (PIMs) in elderly is associated with increased risk of adverse drug reactions (ADRs), potential drug interactions and hospitalizations, which in turn lead to increased cost of therapy and decreased quality of life. ${ }^{2}$ Harugeri et al. reported a prevalence of $32.2 \%$ of ADRs in elderly, which increased the duration of hospital stay in $5.9 \%$ of elderly patients. ${ }^{3}$ Estimates from past studies and long term care settings in elderly found that $27 \%$ of adverse drug reactions in primary care and $42 \%$ of adverse drug events in long term settings were preventable, with most problems occurring at the ordering and monitoring level i.e., at prescribing level. ${ }^{4}$
In order to prevent these medications related hazards associated with PIMs in elderly, it is necessary to identify pattern of prescribing PIMs in a health care setting and the factors associated with it.

The Beer's list identifies these potentially inappropriate medications which should be avoided in elderly aged 65years and above. Initially developed in 1991, the list has gained wide acceptance since then. ${ }^{5}$ In 2012, the Beer's list was updated once again by American geriatric society (AGS) along with 11 interdisciplinary panel experts. The 2012 AGS updated Beer's explicit criteria identified 53 medications as potentially inappropriate, which are divided into 3 Categories: ${ }^{4}$

1. Potentially inappropriate medications and classes to be avoided in older adults. 
2. Potentially inappropriate medications or classes to be avoided in older adults with certain diseases or syndromes.

3. Medications to be used with caution in elderly patients.

Since there is lack of data regarding prescribing PIMs in elderly in this part of country, the present study was undertaken with the objective to determine the prevalence of prescribing PIMs in elderly patients and to determine the factors associated with prescribing PIMs in hospitalised elders.

\section{METHODS}

After getting approval from institutional ethical committee (MDC.DOME/831 dated 14/5/12), the present cross sectional study was undertaken. Case records of elderly patients of either sex aged 65 years or above as on $1^{\text {st }}$ June 2011, who were admitted into general medicine and general surgery wards during third week of June 2011 at a tertiary care hospital were studied. Patients who were put on palliative treatment were excluded as symptom control would take priority in them rather than avoiding inappropriate medications.

The data from case records was collected in proforma which included patient's name, age, sex, inpatient number, date of admission and discharge, presenting complaints, investigations done, diagnosis, and the prescription.

\section{Statistical analysis}

The prevalence of prescriptions having at least one PIM was calculated using Microsoft excel 2007 version. Using bivariate analyses, the predictors of PIMs were identified (independent variables). Multivariate logistic regression was used to evaluate the influence of these independent variables. Statistical analyses were carried out using SPSS version 17.0 software. $\mathrm{p}$ value $<0.05$ was considered statistically significant.

\section{RESULTS}

A total of 132 case records were analysed, and Table 1 describes the demographic details of the sample. Out of 132, 44 patients were prescribed with at least one PIM accounting for a prevalence of $33.3 \%$. A total of 931 drugs were prescribed, out of which 63 (6.7\%) were potentially inappropriate (Figure 1); category I being the most commonly prescribed PIMs (Table 2). Alprazolam was the most commonly prescribed PIM in category I, followed by diclofenac, hyoscine butylbromide (Figure 2). Other medications were from Category II which was ranitidine, diltiazem, and benzodiazepines (Figure 3). None of the prescriptions had category III PIMs.
Table 1: Characteristics of sample population and subgroup of patients with potentially inappropriate medications (PIMs).

\begin{tabular}{|lll|}
\hline $\begin{array}{l}\text { Patient } \\
\text { characteristics }\end{array}$ & Sample & PIMs \\
\hline $\begin{array}{l}\text { Gender } \\
\text { Male }\end{array}$ & $95(69.8 \%)$ & $31(70 \%)$ \\
\hline Female & $41(30.1 \%)$ & $13(30 \%)$ \\
\hline Age & \\
\hline $65-75$ & $28(20.5 \%)$ & $11(24 \%)$ \\
\hline $75-85$ & $69(50.7 \%)$ & $24(54 \%)$ \\
\hline$>85$ & $39(28.6 \%)$ & $9(22 \%)$ \\
\hline $\begin{array}{l}\text { Total number } \\
\text { of medications }\end{array}$ & & \\
\hline 2 & $3(2.2 \%)$ & $1(2.8 \%)$ \\
\hline 3 & $7(4.4 \%)$ & $1(1.4 \%)$ \\
\hline 4 & $11(8.0 \%)$ & $1(2.8 \%)$ \\
\hline 5 & $15(11.0 \%)$ & $3(7 \%)$ \\
\hline 6 and above & $100(73.5 \%)$ & $38(85.9 \%)$ \\
\hline
\end{tabular}

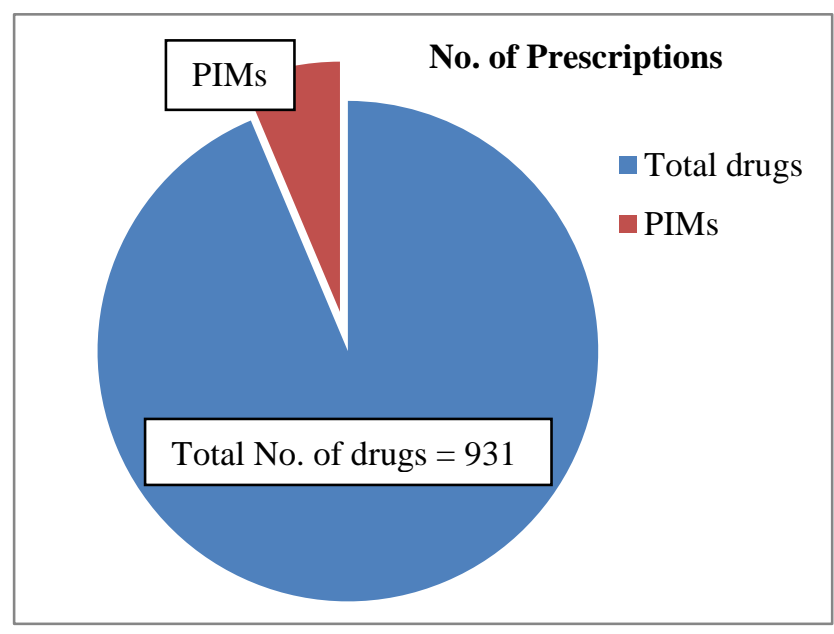

Figure 1: Magnitude of PIMs.

Table 2: Number of PIMs and their frequency.

\begin{tabular}{|ll|}
\hline PIMs as per Beer's criteria 2012 & Total $=\mathbf{6 3}$ \\
\hline Category I & 58 \\
\hline Category II & 5 \\
\hline Category III & 0 \\
\hline
\end{tabular}

Logistic regression analyses were performed to determine the risk factors associated with PIMs. Comparison was made between the groups for polypharmacy ( $>$ or equal to 6 medications) and without polypharmacy (1-5 medications) Results of the logistic regression analysis showed a positive correlation with polypharmacy (OR, 3.66: $95 \%$ CI 1.51-8.89).

Polypharmacy was an independent risk factor associated with inappropriate prescribing. Age and sex had no significant association with prescribing PIMs (Table 3) unlike that studied by Harugeri et al. ${ }^{3}$ 


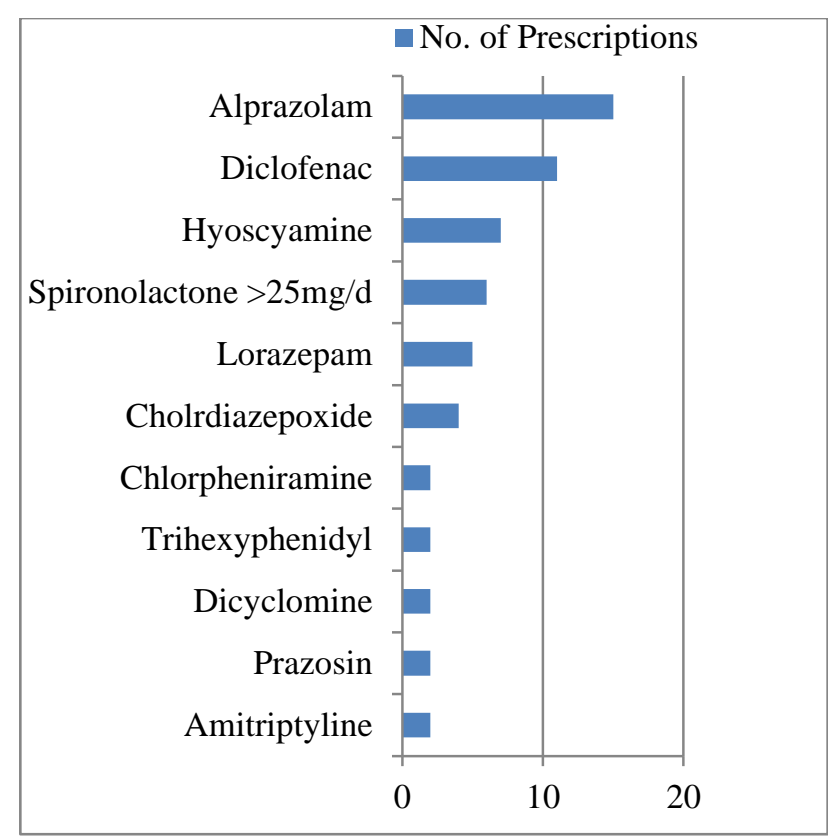

Figure 2: 2012 Beer's criteria for potentially inappropriate medication use in elderly (Category I).

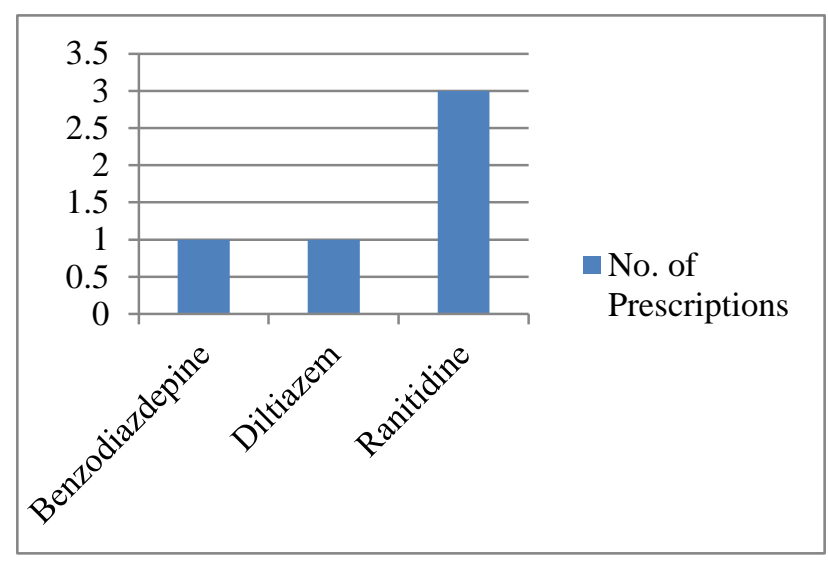

Figure 3: 2012 Beer's criteria for potentially inappropriate Medication use in elderly (Category II).

Table 3: Results of logistic regression analysis.

\begin{tabular}{|llll|}
\hline $\begin{array}{l}\text { Parameter } \\
\text { Gender }\end{array}$ & ODD'S ratio & $\mathbf{9 5 \%}$ CI & P value \\
\hline Male & 0.71 & $0.3-1.65$ & 0.422 \\
\hline Female & 1.00 & Reference & \\
\hline Age & \multicolumn{3}{l|}{} \\
\hline $65-74$ & 1.00 & Reference & \\
\hline $75-85$ & 0.49 & $0.21-1.14$ & 0.09 \\
\hline$>85$ & 0.35 & $0.12-1.04$ & 0.06 \\
\hline $\begin{array}{l}\text { Total } \\
\text { medications }\end{array}$ & & & \\
\hline $1-5$ & 1.00 & Reference & \\
\hline$>6$ & 3.66 & $1.51-8.89$ & $0.004^{*}$ \\
\hline
\end{tabular}

$* \mathrm{p}<0.05$ statistically significant

\section{DISCUSSION}

\section{Prevalence of potentially inappropriate medication}

Our study showed that nearly one in three $(33.3 \%)$ of elderly patients received at least one PIM. The result was slightly higher than another study by Zaveri et al. (23.58\%) using Beer's criteria 2003. ${ }^{2}$ But this was much higher than a study done by Ma et al. (19\%) using 2003 version of Beer's criteria. ${ }^{6}$ This difference could be due to the use of latest version of Beer's criteria 2012 in our study, which had new inclusions like Tab glyburide and sliding scale insulin in category 1 , and glitazones with heart in heart failure, selective serotonin reuptake inhibitors with falls and fractures. ${ }^{4}$

\section{Types of potentially inappropriate medications}

Among PIMs, category I drugs were most commonly prescribed. Alprazolam, diclofenac, hyoscyamine were the most common which should be avoided in elderly irrespective of diagnosis. Taking diagnosis into consideration, Histamine $\mathrm{H}_{2}$ receptor antagonists and calcium channel blockers were identified as potentially inappropriate.

Alprazolam is a short acting benzodiazepine whose elimination half-life increases as age advances, owing to decrease in hepatic clearance. In such cases this will lead to central nervous system side effects like delirium, cognitive impairment, falls, fractures, motor vehicle accidents. It may become appropriate for seizure disorders, rapid eye movement sleep disorders, severe generalised anxiety disorder, peri procedural anaesthesia, end of life care. But, it has to be avoided for treatment of insomnia, agitation, delirium.,

Using diclofenac, a non-cyclooxygenase (COX) selectivenon steroidal anti-inflammatory drug (NSAID) increases the gastrointestinal bleeding, peptic ulcer disease especially if an elderly patient is on corticosteroids, antiplatelets and anticoagulants. Peptic ulcers, gross bleeding or perforation caused by NSAIDs occur in approximately $1 \%$ patients treated for 3-6 months. So it would be better to avoid chronic use of NSAIDs unless other alternatives are not effective and patients can take gastroprotective agents (proton pump inhibitor and misoprostol). ${ }^{4,7}$

Hyoscine butylbromide is a strong anticholinergic drug, with uncertain effectiveness. It can at high dose produce additional anticholinergic effects like dry mouth, visual disturbances, urinary retention, and constipation. So, generally it should be avoided except in short term palliative care to decrease oral secretions. ${ }^{4}$

If spironolactone $>25 \mathrm{mg} /$ day is used, the risk of hyperkalemia increases especially in heart failure patients or those who are on other concomitant drugs like NSAIDs, angiotensin converting enzyme inhibitors, 
angiotensin receptor blockers, or potassium supplements. So, it is better to avoid it in elderly patients especially heart failure and renal failure (creatinine clearance $<30 \mathrm{ml} / \mathrm{min}){ }^{4}$

Anithistaminics (chlorpheniramine) are commonly used in the treatment of allergic rhinitis and common cold. Older antihistaminics such as, promethazine, diphenhydramine are sedating and may cause psychomotor impairment, including eye-hand dis coordination. Their anticholinergic effects also result in visual disturbance, urinary retention, and constipation. However, it is unusual for patients to require long term regular antihistamine treatment. Therefore, both the indications and duration of treatment should be reviewed. ${ }^{6,7}$

Psychotropic medications (anti-depressants, anti-anxiety and hypnotics) were low down in the list of category I PIMs. This is in contrast to another study, ${ }^{8}$ suggesting that inappropriate prescribing of psychotropic medications is not common among local elderly. This is probably due to the pattern of use of psychotropic medications in Chinese and Caucasian populations. Reconsidering these medications while prescribing for elderly has to be done owing to side effects like sedation, orthostatic hypotension and strong anti-cholinergic effects. ${ }^{6}$

Calcium channel blockers (CCBs) are classified as dihydropyridines (nifedipine, amlodipine, and felodipine) and non dihydropyridines (verapamil and diltiazem), which are commonly used in the treatment of hypertension and tachyarrhythmias respectively. Common side effects include flushing, headache, hypotension, constipation. Beta blockers can be considered as alternatives if there are no contraindications. However, in view of clinical efficacy of CCBs as antihypertensives, they may continue to be used because elderly may have multiple comorbidities restricting the use of alternatives (beta blockers or angiotensin converting enzyme inhibitors). Nevertheless, one should be aware of potential side effects in the elderly so that most appropriate drug is prescribed $^{6}$.

\section{Predictors of inappropriate prescribing}

In this study polypharmacy was found to be the risk factor associated with inappropriate prescribing which was in keeping with the findings from other reports. ${ }^{2,6}$ However the cause effect relationship between polypharmacy and PIMs is unclear. Conceivably, the first PIM could cause adverse effects for which secondary drugs are added to alleviate the side effects of the first drug, thus perpetuating a prescription cascade. Alternatively, after balancing the risks and benefits, the complexity of patient's condition may make PIMs necessary, whilst also resulting in polypharmacy. Detailed clinical studies that include sequencing of drug treatment are required to clarify these issues. Nevertheless, review of treatment medications is advisable in patients subjected to polypharmacy, with a view to avoid over prescribing and untoward side effects. Patients aged between 75-85 years had more PIMs than aged $<75$ years and $>85$ years. But this was not statistically significant, and goes in contrast to a study at Hongkong ${ }^{6}$.

\section{Controversy over Beer's explicit criteria}

Beer's criteria though widely used, has certain criteria which needs clarification. For example, trihexyphenidyl/ benztropine are considered potentially inappropriate, but in drug induced parkinson's disease these are the only medications which have to be prescribed.

Our study had some limitations. It was restricted to a particular geographical area of India, so the findings cannot be generalised. Additional studies in other areas and general practice are necessary to raise the awareness among the practitioners about this important public health issue.

The finding from our study that is, one third of elderly were prescribed with inappropriate medication may not become necessarily valid. It is acknowledged that development of explicit criteria is an important means of boosting physician awareness of special issues about prescribing medications, especially for elderly patients who are prone to age- and disease- related pharmacokinetic and pharmacodynamic changes. ${ }^{9,10}$ Explicit criteria should never limit the physician's freedom to prescribe, appropriate clinical evaluation of benefits against risks being of paramount importance in every instance.

Regardless, our study has some merits, including use of updated version of Beer's criteria-2012. We included many specialities to have an overall picture of inappropriate medications.

\section{CONCLUSION}

This study reports that prescribing PIMs is common in elderly. It once again reiterates the need for "geriatric prescription guidelines". It reminds physicians of side effects of commonly prescribed medications when treating elderly patients. Beer's criteria may not suit our Indian elderly patients, in view of different drug pharmacokinetics and pharmacodynamics. Ideally, a group of local experts in geriatric care and pharmacology need to prepare explicit criteria for Indian elderly patients in an effort to avoid unnecessary adverse drug reactions.

Funding: No funding sources

Conflict of interest: None declared

Ethical approval: The study was approved by the institutional ethics committee (MDC.DOME/831 dated 14/5/12) 


\section{REFERENCES}

1. Michael BR, Penelope SP, Fenjuan L, Beatriz KG, Maura JB, Sandra B et al. Potentailly inappropriate medication use in hospitalised elders. J Hosp Medicine. 2008;3(2):91-102.

2. Zaveri HG, Mansuri SM, Patel VJ. Use of potentially inappropriate medicines in elderly: a prospective study in medicine out-patient department of a tertiary care teaching hospital. Indian $\mathbf{J}$ Pharmacol. 2010;42(2):95-8.

3. Harugeri A, Parthasarathi G, Ramesh M, Guido S, Basavanthgowdappa. Frequency and nature of adverse drug reactions in elderly in-patients of two indian medical college hospitals. J Postgrad Med. 2011;57:189-95.

4. Christine M. Campanelli. American geriatric society updated beer's criteria for potentially inappropriate medication in older adults. JAGS. J Am Geriatr Soc. 2012April;60(4):616-31.

5. Cristin R, Denis OM, Julia K, Pter W, Stephen B. Potentially inappropriate prescribing in an irish elderly population in primary care. $\mathrm{Br} \mathrm{J}$ Clin Pharmacol. 2009;68(6):936-47.
6. Ma HM, Lun CM, Dai LK, Kwok CWT, Woo J. Potentially inappropriate medication in elderly patients in outpatient clinics. Asian J Gerontol Geriatr. 2008;3:27-33.

7. Bertram GK. Special aspects of geriatric pharmacology. In: Bertram GK, Susan BM, Anthony JT eds. Basic and Clinical Pharmacology. $11^{\text {th }}$ ed. New Delhi, Tata: McGraw-Hill; 2010: 1037-1044.

8. Curtis LH, Ostbye T, Sendersky V, Hutchison S, Dans PE, Wright A et al. Inappropriate prescribing in elderly Americans in a large outpatient population. Arch Intern Med. 2004;164:1621-5.

9. Lau DT, Kasper JD, Potter DE, Lyles A, Bennett RG. Hospitalization and death associated with potentially inappropriate medication prescriptions among elderly nursing home residents. Arch Intern Med. 2005;165:68-74.

10. Mangoni AA, Jackson SH. Age-related changes in pharmacokinetics and pharmacodynamics: basic principles and practical applications. $\mathrm{Br} \mathrm{J}$ Clin Pharmacol. 2004;57:614.

doi:10.5455/2319-2003.ijbcp20140229

Cite this article as: Bhavya NC, Torgal SS

Potentially inappropriate medications in hospitalised elderly patients: a cross sectional study. Int J Basic Clin Pharmacol 2014;3:215-9. 